\title{
Effects of fiscal consolidation on business confidence in the Euro Area
}

\author{
Nektarios Michail $^{1,2 *} \cdot$ Christos Savva ${ }^{2} \cdot$ Demetris Koursaros $^{2}$ \\ ${ }^{1}$ Central Bank of Cyprus, Cyprus University of Technology, Cyprus \\ ${ }^{2}$ Department of Commerce, Finance and Shipping, Cyprus University of Technology, Cyprus
}

Received: 2 February 2018

Revised: 3 July 2018

Accepted: 3 July 2018

\begin{abstract}
We employ a factor-augmented VAR (FAVAR) covering both domestic and international developments to examine the confidence effects of a fiscal shock, using a sample of six euro area countries. The results indicate that following a shock in total government expenditure, responses are country-specific, while a weak geographical pattern, i.e. a distinction between core and periphery countries can be observed. Overall, the confidence response is short-lived and returns to zero after a few quarters. Heterogeneity in country responses also indicates that the Bachmann and Sims (2012) conclusion suggesting the endogenous response of confidence can explain almost all of the fiscal-driven output expansion in recessions, may hold only in country-specific cases.
\end{abstract}

Keywords: fiscal shocks; FAVAR; expectations

JEL Classification Codes: E30, E61, E62, H30

\section{Introduction}

With the literature on fiscal multipliers tremendously enhanced since the onset of the European sovereign debt crisis, studies on the effects of fiscal consolidations on confidence still remain few, even though it has been documented that confidence has a strong effect on the economy (Bachmann and Sims, 2012; Michail et al., 2017). Of the few existing studies, Beetsma et al (2015), find that, in a panel of OECD countries, consolidations affect consumer confidence negatively. Similar findings were recorded earlier with Konstantinou and Tagkalakis (2011) and Cimadomo et al (2011) showing that expansionary fiscal policy can boost consumer and business confidence.

Other studies do not find similar results. For example, Alesina et al (2015) find that business confidence does not fall much after the start of an expenditure-based adjustment, and subsequently picks up. In contrast, Kalbhenn and Stracca (2015) do not find much evidence

\footnotetext{
* Corresponding author. E-mail: xtarios@gmail.com.

Citation: Michail, N., Savva, C., and Koursaros, D. (2018) Effects of fiscal consolidation on business confidence in the Euro Area, Economics and Business Letters, 7(2), 76-83.
} 
that fiscal consolidations affect variables like confidence and attitude, but they operate only through their effects on the macroeconomy.

Adding to this nascent literature, this paper measures the effect fiscal consolidations have on business sentiment in six euro area countries, using, for the first time in the literature, a factoraugmented VAR (FAVAR) to capture a fuller information set covering both domestic and international developments. The results indicate that following a negative shock in total government expenditure, responses are country-specific and follow only a weak geographical pattern, i.e. a distinction between core and periphery countries can be observed. Overall, the confidence response is short-lived and returns to zero after a few quarters. Heterogeneity in country responses also indicates that the Bachmann and Sims (2012) conclusion suggesting the endogenous response of confidence explaining almost all of the fiscal-driven output expansion in recessions, may hold only in country-specific cases.

\section{Empirical specification}

Let $X_{t}$ denote a $N$ x 1 matrix that contains a large number of economic time series and $Y_{t}$ an $M$ $\mathrm{x} 1$ vector of endogenous variables that are a subset of $X_{t} . F_{t}$ is a $K$ x 1 vector of unobserved factors, which can summarize most of the information contained in $X_{t}$, with $K \ll N$. The joint dynamics of $\left(F_{t}, Y_{t}^{\prime}\right)$ and the static representation of a dynamic factor model $\left(\mathrm{X}_{\mathrm{t}}, \mathrm{F}_{\mathrm{t}}, Y_{t}\right)$ are then given by the following equations:

$$
\begin{aligned}
& {\left[\begin{array}{l}
F_{t} \\
Y_{t}
\end{array}\right]=\Phi(L)\left[\begin{array}{l}
F_{t-1} \\
Y_{t-1}
\end{array}\right]+v_{t}} \\
& X_{t}=\Lambda^{f} F_{t}+\Lambda^{y} Y_{t}+e_{t}
\end{aligned}
$$

Where $\Phi(\mathrm{L})$ is a $(K+M) \times(K+M)$ matrix lag polynomial of finite order $d$ and the error term $v_{t}$ has mean and variance-covariance matrix $Q . \Lambda^{f}$ is a matrix of factor loadings with dimensions $N \times K, \Lambda^{f}$ is $N$ x $M$ and $e_{t}$ is a mean zero vector of errors exhibiting some degree of crosscorrelation. The static representation of the dynamic factor model described by equations (1) and (2), where $F_{t}$ can also include lags of the factors, is estimated with the principal components method (Stock and Watson 1998, 2002 and 2005). The FAVAR model succeeds in overcoming the deficiency of information in standard VAR models (Bernanke et al. 2005) and, and has consequently been employed in a wide variety of studies (e.g. Lombardi et al, 2012; Belke and Rees, 2014; Ferland et al, 2014; Belke and Osowski, 2017). Furthermore, the FAVAR responses to a spending shock are not Granger-caused by government spending forecasts and thus do not suffer from foresight issues (see Forni and Gambetti, 2010; Forni et al, 2009).

The choice of variables, as well as the ordering, is also related to the transmission channels through which sentiment affects the economy, as these have been suggested by the existing literature. In particular, as Akerlof and Shiller (2009), suggest, surprise fluctuations in beliefs may temporarily affect economic activity. Furthermore, Blanchard (1993) considers exogenous movements in consumer confidence as a cause of business cycles, while Barsky and Sims (2012) find that that confidence shocks are associated with a modest immediate response of real activity in the US. Importantly, Lorenzoni (2009) suggests that households could fail to perfectly observe fundamentals, but use observables like aggregate output to form beliefs about their true values. To this end, fiscal (and monetary) authorities could implement expansive policies as a way to signal that fundamentals have improved. In other words, boosting confidence could assist in a faster recovery.

Following the findings of the literature, the examination of the effects of fiscal consolidation on confidence is explored using a VAR model with six endogenous variables: final consumption expenditure of general government $(\mathrm{G})$, total taxation revenue $(\mathrm{T})$, the business sentiment 
index $(\mathrm{S})$ consumer price index $(\mathrm{P})$, interest rate measured by the 10 -year government bond yield (R), real GDP (Y), and gross government debt (D). A similar variable ordering, where macro series such as output and prices respond contemporaneously to a fiscal shock, is followed in other works studying the effects of fiscal policy (e.g. Giordano et al., 2007, Perotti, 2004, Blanchard and Perroti, 2002; Cimadomo and Bénassy-Quéré, 2012). Government debt has been included to address the fiscal contraction hypothesis according to which confidence should increase in the wake of fiscal consolidations, especially when debt is high (Giavazzi and Pagano, 1990, De Castro, 2006; Favero and Giavazzi, 2007; Kameda, 2012; Favero and Giavazzi, 2012). ${ }^{1}$ As regards the sentiment variable employed, business confidence appears to have a greater impact than consumer confidence (Beckmann et al., 2011) hence justifying the selection of this index.

Government debt has been included to address the fiscal contraction hypothesis according to which confidence should increase in the wake of fiscal consolidations, especially when debt is high (Giavazzi and Pagano, 1990, De Castro, 2006; Favero and Giavazzi, 2007; Kameda, 2012; Favero and Giavazzi, 2012). ${ }^{2}$ As regards the sentiment variable employed, business confidence appears to have a greater impact than consumer confidence (Beckmann et al., 2011) hence justifying the selection of this index.

These are augmented with a series of local (extracted from a dataset of domestic series) and global (from a group of foreign and international variables) factors, with the number of factors in each case chosen using the Bai and Ng (2002) criteria. The lag order was chosen based on the Scwarz and Akaike information criteria. Identification is achieved by employing a recursive ordering of the variables, with the contemporaneous dependence of domestic factors on foreign factors and $Y_{\mathrm{t}}$ removed.

The estimated FAVAR model is used to simulate the responses to a negative one percent shock to total government expenditure. To ensure comparability of results, all variables are standardised before the estimation and a $1 \%$ shock is implemented. Confidence intervals were calculated via the Kilian (1998) bootstrap-after-bootstrap method.

\section{Data}

In order to test for the effects of policy and expectations, we employ data for six Euro Area economies (Germany, Greece, Italy, the Netherlands, Portugal and Spain). In total, 75 variables are employed to capture the international effects. Furthermore, in order to extract the local factors which drive the economy, 83 time-series variables are used for Germany (1998 Q12012Q3), 63 for Greece (1998Q2-2012Q3), 84 for Italy (1998Q1-2012Q3), 70 for the Netherlands (1998Q1-2012Q3), 81 for Portugal (1998Q1-2012Q3) and 62 for Spain (1998Q12012Q3). The span of the sample reflects data availability. The variables and transformations employed to ensure stationarity for all sample countries can be found in the Appendix accompanying this paper.

\section{Results}

To first motivate the points raised in this paper, Figure 1 shows the real GDP responses following a negative business confidence shock. As the results suggest, the responses are negative and statistically significant in all countries, reaching values close to $1 \%$ of GDP in the long-run.

\footnotetext{
${ }^{1}$ Robustness checks, pertaining to changes in the lag order, rolling window estimates, and the number of factors selected on the basis of the information criteria have also been conducted. The results from these exercises are qualitatively similar and hence reach very similar conclusions. Results are available upon request.

${ }^{2}$ Robustness checks, pertaining to changes in the lag order, rolling window estimates, and the number of factors selected on the basis of the information criteria have also been conducted. The results from these exercises are qualitatively similar and hence reach very similar conclusions. Results are available upon request.
} 
The result, in line with Michail et al. (2017) and Barksy and Sims (2012) highlights the fact that business confidence plays an important role in the economy.

Figure 1. Real GDP response to a negative business confidence shock.

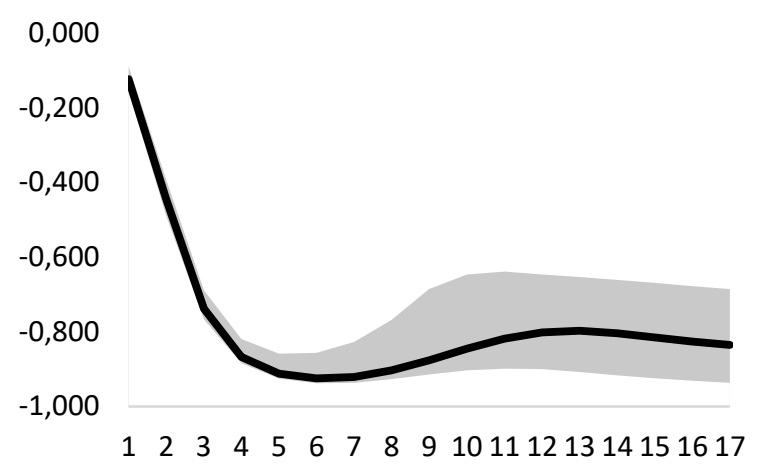

(a) Germany

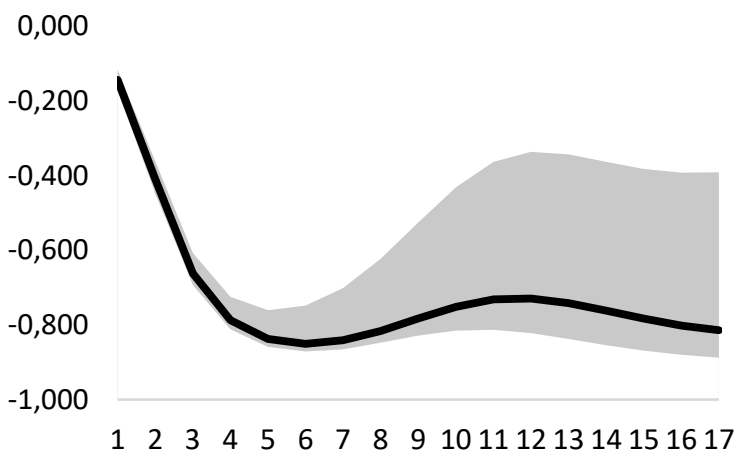

(c) Italy

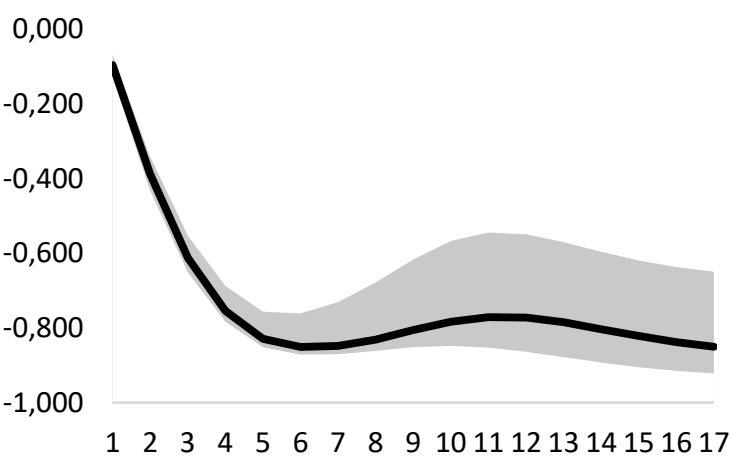

(e) Portugal

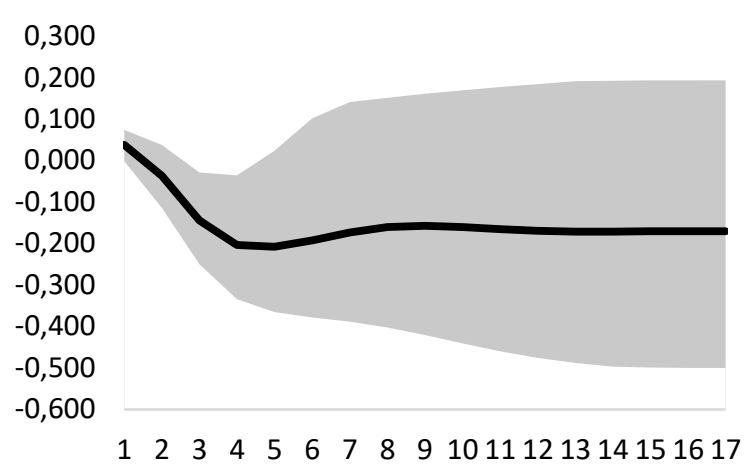

(b) Greece

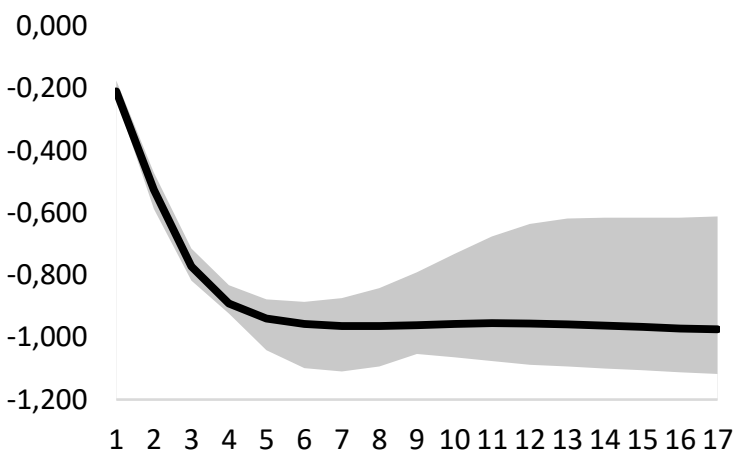

(d) Netherlands

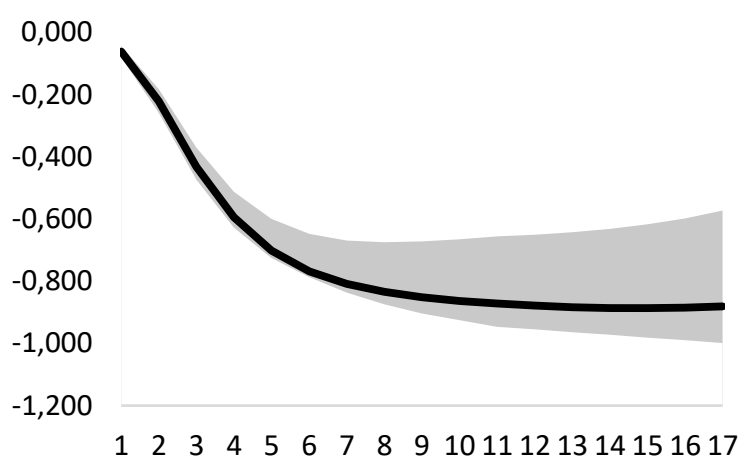

(f) Spain

The main point of this paper is summarised in Figure 2, which depicts the response of business confidence in the six euro-area countries following a $1 \%$ negative shock in government spending. When looking at the path of the responses there appears to be a clear distinction between core euro area countries and periphery ones: in Italy, Portugal, Spain and Greece the response is overall negative while Germany and the Netherlands register positive responses. The distinction remains once we examine for statistical significance, given that one core and two periphery countries register positive and negative responses respectively.

In particular, Germany is the only country in which a negative government spending shock leads to an increase in business confidence. In contrast, Italy and Greece register negative and significant response following a negative spending shock. Finally, the Netherlands and Spain register a positive and significant response only in the first quarter while Portugal shows an insignificant response. For the countries which register a significant response, this appears to 
be short-lived, lasting six quarters at most, as expected given the non-permanent nature of expectations variables, given that as Beaudry and Portier (2006) have shown, innovations to confidence largely reflect news about future fundamentals which tend to be transitory by nature. Hence, the conclusion to be drawn from Figure 1 is that while a fiscal shock can have an initial strong effect on business confidence (either positive or negative), this effect is not persistent. The results provide only weak support to the suggestions of Bachmann and Sims (2012) that the endogenous response of confidence explains almost all of the fiscal-driven output expansion in recessions. While this appears to hold in Italy and Greece, the German response points to the other direction, albeit with the caveat that Germany only faced five down quarters during the whole sample period.

Figure 2. Business confidence response to a negative government spending shock.

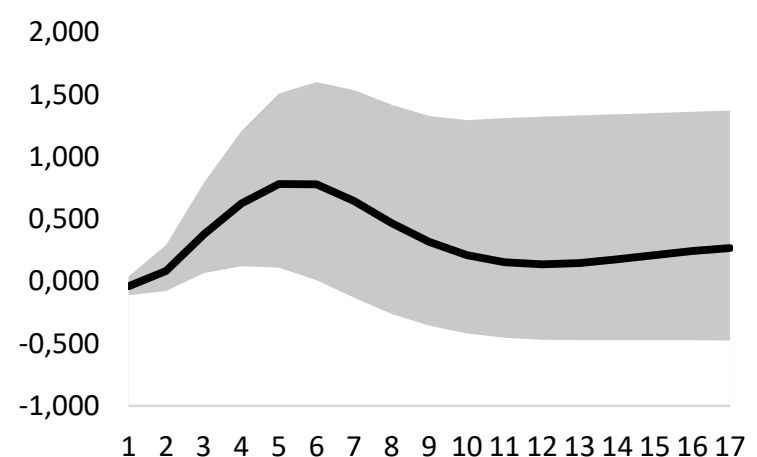

(a) Germany

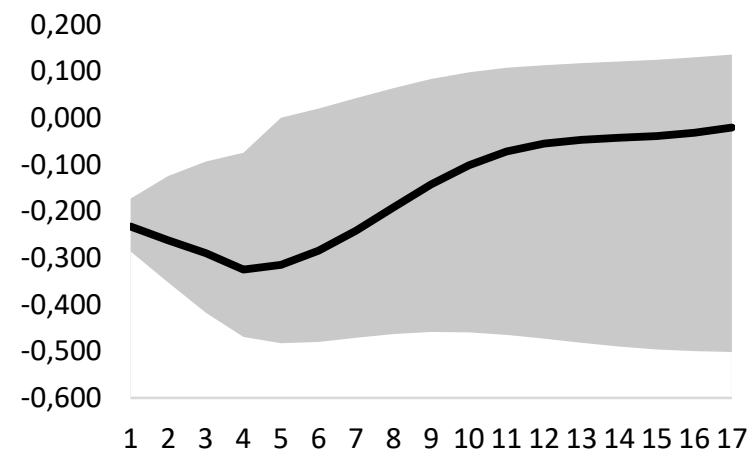

(c) Italy

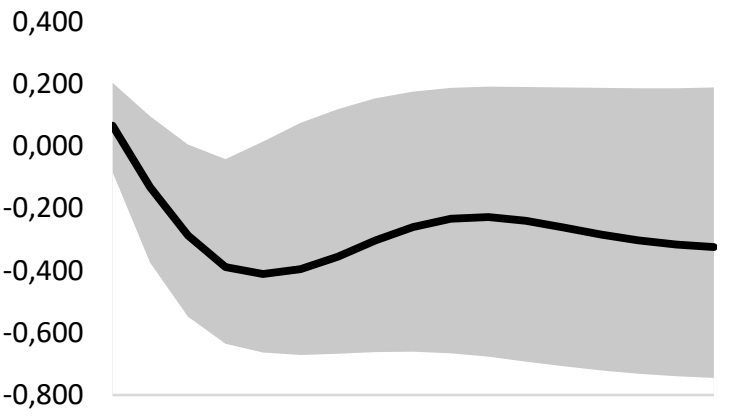

$\begin{array}{llllllllllll}1 & 2 & 3 & 4 & 5 & 6 & 7 & 8 & 9 & 1011 & 121314151617\end{array}$

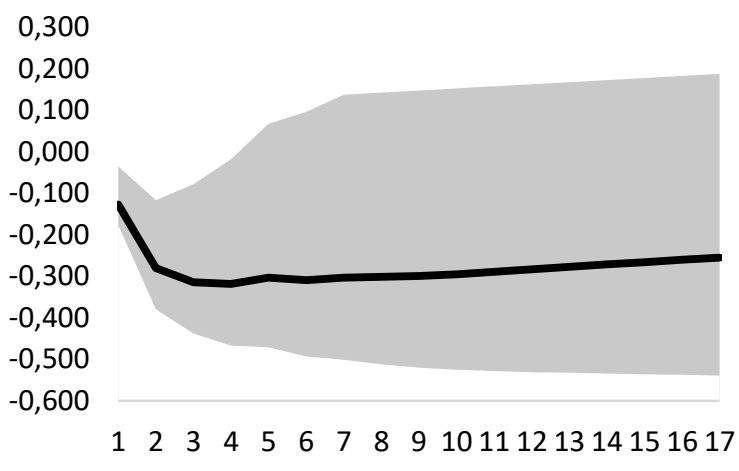

(b) Greece

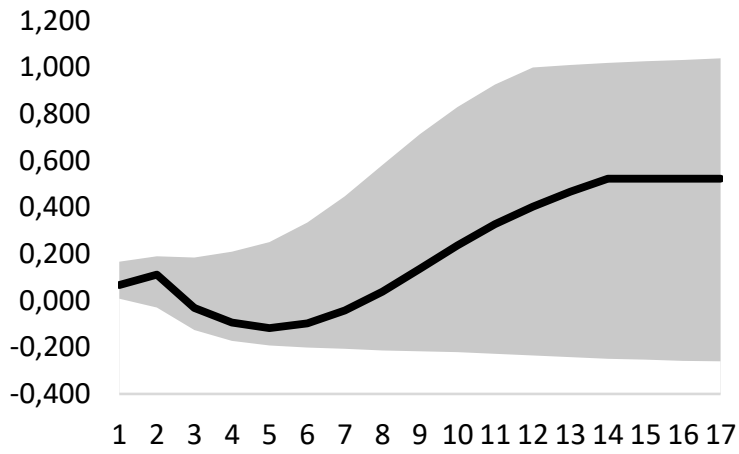

(d) Netherlands

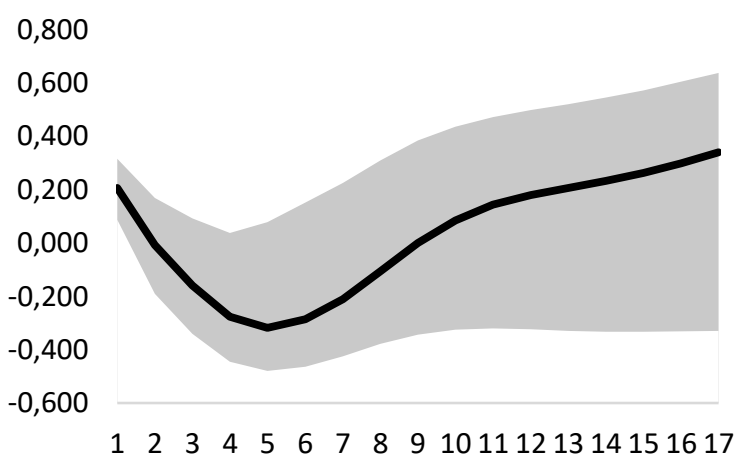

(f) Spain

As suggested earlier, Figure 3 aims at examining whether, following the results of Kasselaki and Tagkalakis (2016), tax-based fiscal consolidation has a different effect on business confidence relative to an expenditure-based fiscal consolidation. As the results indicate, business confidence increases in Germany, Italy and Spain, while an insignificant response is found 
in the remaining three countries. Interestingly, Germany is only the country where "negative" fiscal developments (reductions in spending and/or increases in taxation) suggest a positive confidence response. In contrast, while a taxation shock increases business confidence in Italy, a negative government shock would decrease it as Figure 1 has showed. In Greece, the Netherlands and Portugal the response from a taxation shock appears to be insignificant. Overall, the conclusions of Kasselaki and Tagkalakis (2016) do not appear to hold for business confidence as a positive relationship appears to hold between an increase in taxation and business confidence, perhaps due to the fact that more taxation can be less harmful, ceteris paribus, to the economy, given that only if private spending takes place will there be a corresponding increase in taxation income. To this end, future research could perhaps employ specific tax rates which would be more useful in correctly specifying this relationship.

Figure 3. Business confidence response to an increase in taxation income.

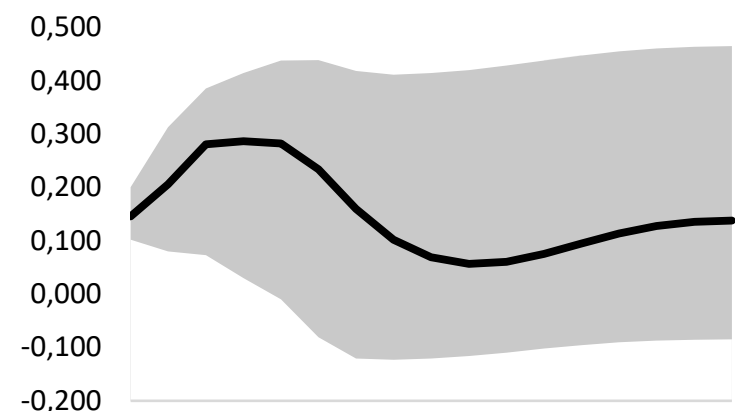

$1 \quad 2 \quad 3 \quad 4 \quad 5 \quad 6 \quad 7 \quad 8 \quad 91011121314151617$

(a) Germany

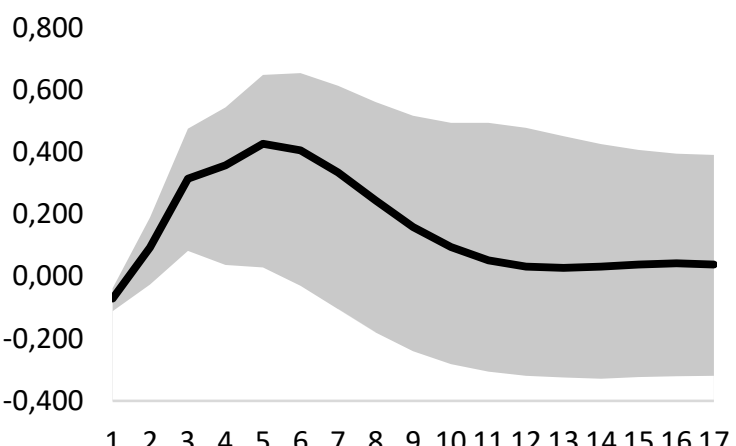

(c) Italy

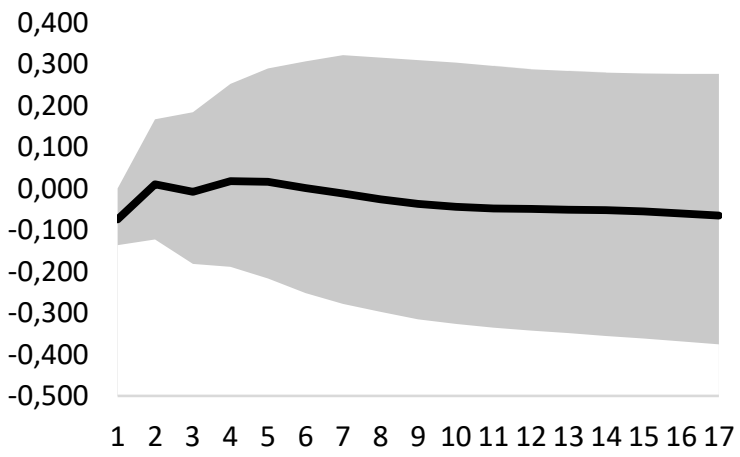

(e) Portugal

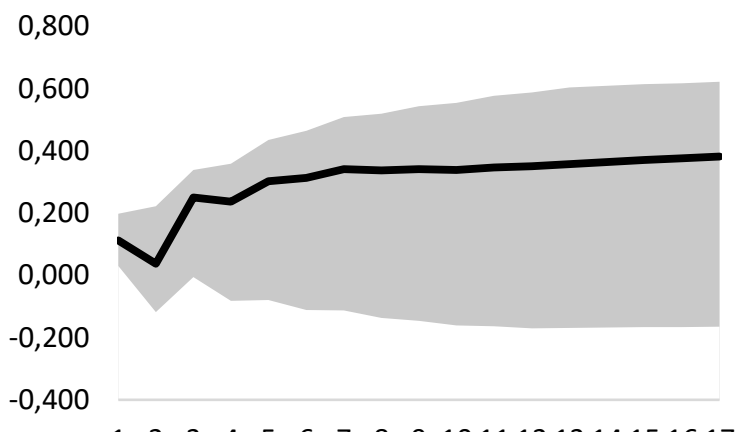

(b) Greece

0,400

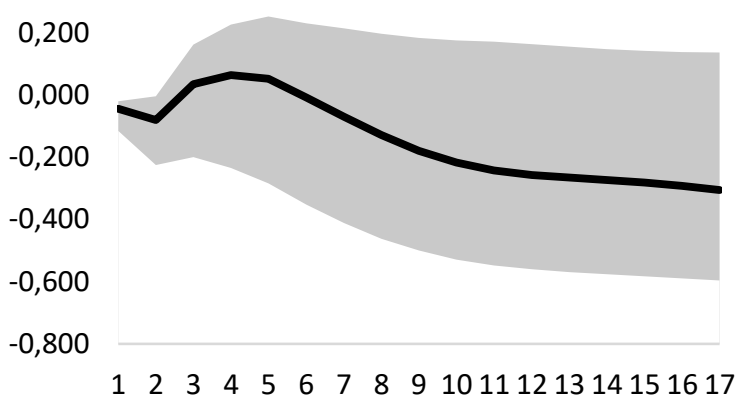

(d) Netherlands

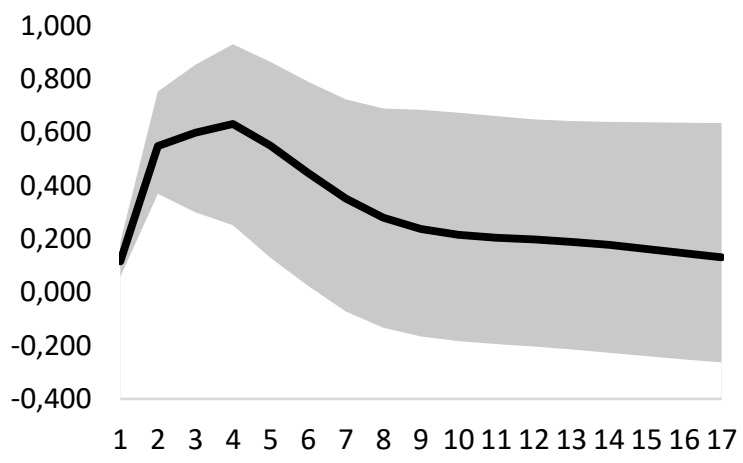

(f) Spain

\section{Concluding remarks}

Summing up from the previous section, the results point out that in the case of fiscal consolidation there is important heterogeneity in the response of business sentiment in the euro area 
countries. In the countries where the response is not zero the effect is short-lived, usually dying out after the second year. Since "the Keynesian short-run is the timeframe of politics" as O'Rourke and Taylor (2013) comment, fiscal consolidation could, in some specific cases, amplify its impact on the economy through the confidence channel, similar to what Bachmann and Sims (2012) suggest. The results of this paper have important policy implications as ignoring the effect fiscal consolidations can have on business confidence could severely understate the forecasts made. Perhaps a test of whether including business confidence in forecast equations would lead to better estimates would be a useful extension of the findings.

\section{References}

Akerlof, G., and Shiller, R. (2009) Animal Spirits: How Human Psychology Drives the Economy, and Why It Matters for Global Capitalism, Princeton University Press.

Alesina, A., Favero, C., and Giavazzi, F. (2015) The output effect of fiscal consolidation plans, Journal of International Economics, 96(S1), S19-S42.

Bachmann, R., and Sims, E. R. (2012) Confidence and the transmission of government spending shocks, Journal of Monetary Economics, 59(3), 235-249.

Bai, J., and Ng S. (2002) Determining the Number of Factors in Approximate Factor Models. Econometrica 70(1), 191-221.

Barsky, R. B., and Sims, E. R. (2012) Information, Animal Spirits, and the Meaning of Innovations in Consumer Confidence, American Economic Review, 102(4), 1343-1377.

Beetsma, R., Cimadomo, J., Furtuna, O., and Giuliodori, M. (2015) The confidence effects of fiscal consolidations, Economic Policy, 30(83), 439-489.

Belke, A., and Osowski, T. (2017) International Effects of Euro Area versus US Policy Uncertainty: A FAVAR Approach, GLO Working Paper No. 35, Global Labor Organization.

Belke, A., and Rees, A. (2014) Globalisation and Monetary Policy - A FAVAR Analysis for the G7 and the Euro Area, North American Journal of Economics and Finance, 29, 306-321.

Beckmann, J., Belke, A., and Kuehl, M. (2011) Global Integration of Central and Eastern European Financial Markets - The Role of Economic Sentiments, Review of International Economics, 19(1), 137-157.

Bernanke, B. S., Boivin, J. and Eliasz, P. (2005) Measuring the effects of monetary policy: a factor-augmented vector autoregressive (FAVAR) approach, Quarterly Journal of Economics, 120(1), 387-422.

Blanchard, O., and Perotti, R. (2002) An Empirical Characterization of the Dynamic Effects of Changes in Government Spending and Taxes on Output, Quarterly Journal of Economics, 117(4), 1329-1368.

Cimadomo, J., Hauptmeier, S., and Sola, S. (2011), Identifying the Effects of Government Spending Shocks with and without Expected Reversal: an Approach Based on U.S. RealTime Data, ECB Working Paper, No. 1361.

De Castro, F. (2006) The macroeconomic effects of fiscal policy in Spain, Applied Economics, 38, 913-924.

Favero C., and Giavazzi F. (2007) Debt and the effects of fiscal policy. NBER Working Paper No. 12822.

Favero C., and Giavazzi F. (2012) Measuring tax multipliers: the narrative method in fiscal VARs, American Economic Journal: Economic Policy, 4(2), 69-94.

Fernald, J. G., Spiegel, M. M., and Swanson, E. T. (2014) Monetary policy effectiveness in China: Evidence from a FAVAR model, Journal of International Money and Finance, 49(Dec), 83-103. 
Forni, M., and Gambetti, L. (2010). Fiscal foresight and the effects of government spending. Mimeo. University of Modena and University Autonoma de Barcelona.

Forni, M., Giannone, D., Lippi, M., and Reichlin, L. (2009) Opening the Black Box: Structural Factor Models with Large Cross-Sections, Econometric Theory, 25(5), 1319-1347.

Giavazzi, F., and Pagano, M. (1990) Can Severe Fiscal Contractions Be Expansionary? Tales of Two Small European Countries, NBER Macroeconomics Annual, 5, 75-111.

Giordano, R., Momigliano, S., Neri, S., and Perotti, R. (2007) The effects of fiscal policy in Italy: Evidence from a VAR model, European Journal of Political Economy, 23(3), 707-733.

Kalbhenn, A., and Stracca, L. (2014) Does Fiscal Austerity Affect Public Opinion?, European Central Bank, Mimeo.

Kameda, K. (2012) Estimating Non-Keynesian Effects for Japan, Asian Economic Policy Review, 7(2), 227-243.

Kasselaki M., and Tagkalakis, A. (2016) Fiscal policy and private investment in Greece, International Economics, 147(C), 53-106.

Kilian, L. (1998) Small-sample confidence intervals for impulse response functions, Review of Economics and Statistics, 80(2), 218-230.

Konstantinou, P., and Tagkalakis, A. (2011) Boosting confidence: is there a role for fiscal policy?, Economic Modelling 28(4), 1629-1641.

Lombardi, M. J., Osbat, C., and Schnatz, B. (2012) Global commodity cycles and linkages: a FAVAR approach, Empirical Economics, 43(2), 651-670.

Lorenzoni, G. (2009) A Theory of Demand Shocks, American Economic Review, 99(5), 205084.

Michail, N. A., Savva, C. S., and Koursaros, D. (2017) Size Effects of Fiscal Policy and Business Confidence in the Euro Area. International Journal of Financial Studies, 5(4), 26.

O'Rourke, K. H., and Taylor, A. M. (2013) Cross of Euros, Journal of Economic Perspectives, 27(3), 167-192.

Perotti, R. (2004) Estimating the effects of fiscal policy in OECD countries, IGIER Working Paper no. 276.

Stock, J., and Watson, M. (1998) Diffusion Indexes, NBER Working Papers No. 6702.

Stock, J., and Watson, M. (2002) Macroeconomic Forecasting Using Diffusion Indexes, Journal of Business and Economics Statistics, 20(2), 147-162.

Stock, J., and Watson, M. (2005) Implications of Dynamic Factor Models for VAR analysis, NBERWorking Papers No. 11467. 